\title{
Identificação da suscetibilidade antimicrobiana de bactérias isoladas de cães e gatos com feridas traumáticas contaminadas e infectadas
}

\section{Identification of antimicrobial susceptibility of bacteria recovered from dogs and cats with contaminated and infected traumatic wounds}

\author{
Mônica Vicky Bahr Arias ${ }^{1 *}$; Luana de Assis Battaglia²; Graciane Aiello \\ Thacyana Teixeira de Carvalho ${ }^{2}$; Julio César de Freitas ${ }^{4}$
}

\begin{abstract}
Resumo
As feridas traumáticas em cães e gatos são freqüentes na rotina da clínica veterinária. Em sua maioria são decorrentes de mordidas e atropelamentos. Muitas dessas feridas tornam-se contaminadas ou infectadas, não respondendo ao tratamento utilizado. Os objetivos deste trabalho foram avaliar os dados de animais com feridas traumáticas contaminadas e infectadas que apresentaram complicações durante o tratamento, como aumento da secreção, alteração da sua cor ou cicatrização inadequada, identificar as bactérias presentes nestas feridas e sua suscetibilidade a antibióticos e verificar se os antibióticos utilizados no início do tratamento eram adequados. Para isso realizou-se o acompanhamento de 18 animais (17 cães e um gato) com ferimentos de origem traumática, que não apresentaram boa evolução do quadro com o tratamento tópico e sistêmico instituído. Realizou-se a coleta da secreção de cada ferida com swab e posterior cultura em ágar sangue, obtendo-se 20 isolados bacterianos. Os bacilos Gram negativos foram detectadas em $70 \%$ dos casos, sendo Pseudomonas o gênero predominante (30\%), seguido pelo Proteus (20\%). Dentre os Gram positivos (30\% dos casos), Staphylococus e Streptococcus foram isolados com igual freqüência. Verificou-se susceptibilidade muito baixa das bactérias encontradas aos antimicrobianos testados ( $7 \%$ a 58,33\%), enfatizando a necessidade de realização destes testes em bactérias isoladas de animais com ferimentos contaminados e infectados que não respondem adequadamente ao tratamento tópico e sistêmico.
\end{abstract}

Palavras-chave: Feridas, cães, gatos, infecção, bactérias, antibiograma

\begin{abstract}
Traumatic wounds in dogs and cats are frequent in a clinician veterinarian's routine. Most of them occur due to either bites from other animals or car accidents. As a result, many wounds become contaminated or infected and do not respond to treatment. The objectives of this study were to evaluate animals with traumatic wounds that present such complications during treatment as increased secretions, change in the color of these secretions or unsuitable healing, to identify bacteria in those wounds and their susceptibility to antimicrobials, and to verify if antimicrobial therapy instituted earlier in the treatment was adequate. To reach this, 18 animals (17 dogs and one cat) with traumatic wounds that presented an unsatisfactory healing process after topic and systemic treatment were used. In these cases, a swab from the wound secretion and bacterial culture in blood agar were performed. Twenty bacterial isolates were obtained. Gram negative bacilli were found in $70 \%$ of the cases, and Pseudomonas was the
\end{abstract}

1 Prof . Adjunta, Disciplinas de Técnica e Clínica Cirúrgica de Pequenos Animais, Departamento de Clínicas Veterinárias, Universidade Estadual de Londrina. E-mail: vicky@uel.br.

2 Discente, curso de Medicina Veterinária, Universidade Estadual de Londrina, bolsista, PIBIC-UEL.

3 Discente, curso de Medicina Veterinária, Universidade Estadual de Londrina, Bolsista CNPQ.

4 Prof. Titular, Departamento de Medicina Veterinária Preventiva, UEL

* Autor para correspondência 
predominant gender (30\%), followed by Proteus (20\%). Among the gram positive group (30\% of the cases) Staphylococcus and Streptococcus were found with the same frequency. A very low susceptibility ( $7 \%$ to $53,33 \%$ ) of bacteria isolates to the tested antimicrobial drugs was found, emphasizing the need for carrying out these tests in bacteria isolated from animals with contaminated and infected wounds that do not respond to topic and systemic treatments.

Key words: Wounds, dogs, cats, infection, bacterial, antibiogram

\section{Introdução}

As feridas traumáticas em cães e gatos são freqüentes na rotina da clínica veterinária e na maior parte dos casos, são decorrentes de mordidas de outros animais ou atropelamentos. Segundo Arias e Pereira (2002) e Dernell (2006) as feridas podem ser classificadas de acordo com o tempo decorrido desde o trauma e o grau de contaminação em contaminadas (6 a 12 horas de duração, com debris celulares, sem exsudato) ou infectadas (mais de 12 horas de duração, processo infeccioso com presença de exsudato, tecidos desvitalizados, corpos estranhos e pus). Recomenda-se o tratamento destas feridas na forma aberta, por meio da realização de lavagem, debridamento e troca de bandagens diárias (HEDLUND, 1997; ARIAS; PEREIRA, 2002).

A presença de bactérias em uma ferida não significa necessariamente infecção. A maioria das feridas manejadas na forma aberta com limpeza diária e bandagens evolui bem, porém fatores relacionados ao paciente como idade, imunossupressão, doenças concomitantes, tipo, quantidade e virulência dos microorganismos presentes influenciam a evolução do quadro (HEDLUND, 1997; ARIAS; PEREIRA, 2002). Nestes casos o médico veterinário deve decidir pelo uso de antibióticos, com o objetivo de controlar a colonização microbiana, reduzir seu potencial invasivo e prevenir a septicemia (DAVIDSON, 1998a). A seleção do antibiótico deve ser feita com base nos sinais clínicos, tipo de lesão e resultados da cultura e antibiograma (DAVIDSON, 1998b).

Os objetivos deste trabalho foram avaliar os dados de pacientes com feridas traumáticas contaminadas e infectadas que apresentaram complicações durante o tratamento, como aumento da secreção purulenta, alteração da sua cor ou cicatrização inadequada, identificar as bactérias presentes nestas feridas, sua suscetibilidade a antibióticos e verificar se os antibióticos utilizados no início do tratamento eram adequados.

\section{Materiais e Métodos}

Seleção dos casos

O trabalho foi desenvolvido por meio do acompanhamento de 18 animais (17 cães e um gato) internados na enfermaria do Centro Cirúrgico do Hospital Veterinário (HV) da Universidade Estadual de Londrina (UEL) no período de 09/2006 a 04/2007, com feridas de origem traumática. Estes casos foram selecionados dentre todos os animais internados no mesmo período com ferimentos contaminados ou infectados, por apresentarem aumento da secreção, surgimento de secreção de coloração esverdeada, não evolução da cicatrização ou alterações sistêmicas indicando piora do quadro. Todos os casos internados neste período foram acompanhados através do preenchimento de uma ficha constando Registro Geral no HV, espécie, raça, sexo, idade, motivo do internamento, dados sobre o tipo e duração da ferida, tempo decorrido entre o trauma e o atendimento, classificação das feridas traumáticas, tempo de internamento, antibióticos e produtos tópicos utilizados pelo proprietário antes do atendimento, tipo de bandagem, alterações clínicas e resultados de cultura e antibiograma. 


\section{Tratamento inicial}

O tratamento tópico foi instituído no momento do atendimento inicial no HV/UEL e constou de lavagem das feridas com solução fisiológica $0,9 \%$ estéril, debridamento cirúrgico quando indicado e aplicação de bandagens aderentes ou não aderentes de acordo com o estágio da cicatrização. O tratamento sistêmico constou de antibioticoterapia escolhida conforme o tipo e causa da ferida, associado à analgesia e hidratação quando necessário.

\section{Coleta de amostras}

A coleta da secreção das feridas foi feita por swab estéril. Foram realizadas 20 culturas nos 18 pacientes, sendo 19 de feridas cutâneas e uma de líquido pleural conseqüente à ferida perfurante em tórax, das quais foram obtidas 19 culturas positivas e uma negativa, com um total de 20 isolados bacterianos.

\section{Procedimentos bacteriológicos}

A identificação dos microrganismos foi realizada segundo as características culturais, morfológicas, tintoriais e bioquímicas (CARTER, 1988). A sensibilidade antimicrobiana foi realizada no meio Muller Hinton, pelo método de difusão em placas com discos (BAUER; KIRBY; SHERRIS, 1966). Os antibióticos testados foram amicacina 30mcg (14 culturas), amoxacilina $10 \mathrm{mcg}$, amoxacilina+ácido clavulônico $30 \mathrm{mcg}$ (11 culturas), ampicilina 10 mcg (12 culturas), cefalexina $30 \mathrm{mcg}$ (17 culturas), cefalotina $30 \mathrm{mcg}$ (sete culturas), ceftiofur 30 mcg (quatro culturas), ciprofloxacina $05 \mathrm{mcg}$ (17 culturas), clindamicina $02 \mathrm{mcg}$ (três culturas), enrofloxacina $05 \mathrm{mcg}$ ( 20 culturas), espectinomicina $300 \mathrm{mcg}$ (duas culturas), gentamicina $10 \mathrm{mcg}$ (11 culturas), lincomicina $02 \mathrm{mcg}$ (três culturas), nitrofurantoína $10 \mathrm{mcg}$ (três culturas), norfloxacina mcg (12 culturas), orbifloxacina $10 \mathrm{mcg}$ (duas culturas), penicilina $10 \mathrm{U}$ (quatro culturas) e sulfazotrim $25 \mu \mathrm{g}$ (13 culturas). Após a realização da cultura e antibiograma do material coletado das feridas, foi verificada a necessidade de alteração do tratamento de acordo com o quadro clínico, comparando-se o antibiótico utilizado previamente ao resultado do antibiograma.

$\mathrm{O}$ índice MAR (múltipla resistência antimicrobiana) foi utilizado para determinação da múltipla resistência dos microorganismos. Este índice é definido como $\mathrm{a} / \mathrm{b}$, ou seja, o número de antibióticos aos quais o isolado foi resistente (a), dividido pelo número de antibióticos aos quais o isolado foi exposto (b). Índice MAR acima de 0,2 caracteriza multiresistência (KRUMPERMAN, 1983).

\section{Resultados}

\section{Dados clínicos-terapêuticos iniciais}

Ao verificar-se a causa das feridas foi constatado que metade decorreu de mordidas e 11 já estavam infectadas no atendimento inicial, sendo que todas as infectadas apresentavam mais de seis horas de duração, com média de 37 horas. Seis pacientes apresentaram alterações sistêmicas como anemia e/ ou trombocitopenia ou leucocitose e um apresentava doença auto-imune, recebendo corticóides há mais de três meses (Quadro 1). 


\begin{tabular}{|c|c|c|c|c|c|c|c|c|c|c|c|c|c|c|c|c|c|c|c|c|}
\hline 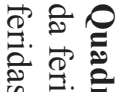 & 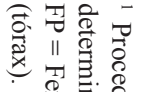 & $\vec{\infty}^{-}$ & $\exists$ & $\sigma$ & $\vec{u}$ & $\nexists$ & $\vec{\omega}$ & $\bar{N}$ & $=$ & $\vec{\sigma}$ & 0 & $\infty$ & $\checkmark$ & $a$ & ur & $\rightarrow$ & $\omega$ & $N$ & - & 胥. \\
\hline 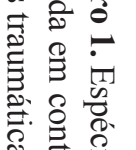 & 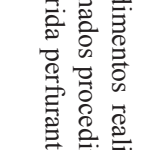 & 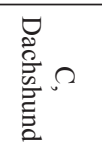 & $\begin{array}{l}\Omega \\
\tilde{\theta}\end{array}$ & $\begin{array}{l}\Omega \\
\tilde{\theta}\end{array}$ & 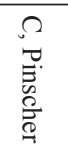 & 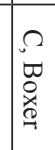 & $\begin{array}{l}\Omega \\
\tilde{0}\end{array}$ & $\begin{array}{l}\hat{\mathscr{Z}} \\
\tilde{\theta}\end{array}$ & $\begin{array}{l}\Omega \\
\sim \\
\tilde{\theta}\end{array}$ & $\begin{array}{l}\Omega \\
\mathscr{Z}\end{array}$ & $\begin{array}{l}\Omega \\
\ddot{0} \\
0\end{array}$ & 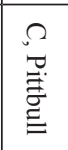 & $\begin{array}{l}\Omega \\
0 \\
0 \\
\frac{0}{0}\end{array}$ & 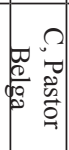 & $\begin{array}{l}\Omega \\
0 \\
0 \\
0\end{array}$ & 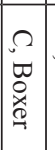 & $\begin{array}{l}\Omega \\
2 \\
\tilde{\theta}\end{array}$ & $\begin{array}{l}\Omega \\
\tilde{\theta} \\
\theta\end{array}$ & $\begin{array}{l}\pi \\
y \\
0 \\
\theta\end{array}$ & 要 \\
\hline 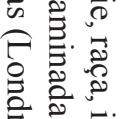 & 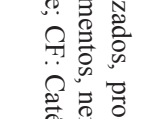 & 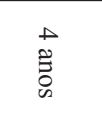 & $\begin{array}{l}N \\
\tilde{z} \\
\tilde{\omega}\end{array}$ & & ' & $\overrightarrow{\tilde{z}}$ & 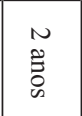 & $\begin{array}{l}u \\
0 \\
\tilde{z} \\
0\end{array}$ & 点 & vै & $\begin{array}{l}\bar{\omega} \\
\tilde{0} \\
\vdots \\
\vdots\end{array}$ & $\begin{array}{l}\omega \\
\tilde{\omega} \\
\tilde{\omega}\end{array}$ & $\begin{array}{l}\text { ० } \\
\vdots 0 \\
0 \\
0\end{array}$ & ' & $\begin{array}{l}u \\
0 \\
\tilde{z} \\
0 \\
0\end{array}$ & 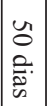 & 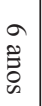 & $\begin{array}{l}a \\
\tilde{z} \\
0 \\
\infty\end{array}$ & 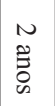 & 产 \\
\hline 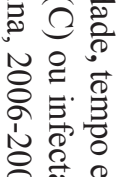 & 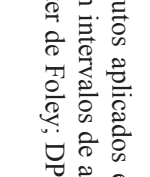 & $\overrightarrow{\sigma_{\overparen{*}}}$ & $\overrightarrow{\mathrm{\partial}}$ & 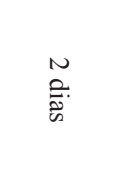 & 至 & $\vec{b}$ & 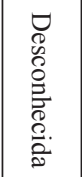 & 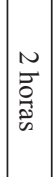 & 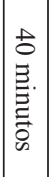 & $\vec{z}$ & $\overrightarrow{\mathrm{\partial}}$ & N & $\begin{array}{l}\infty \\
\stackrel{2}{2} \\
\hat{2}\end{array}$ & $\begin{array}{l}\bar{n} \\
\bar{\partial} \\
\bar{\omega}\end{array}$ & 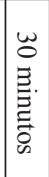 & 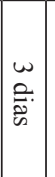 & $\vec{\Xi}$ & 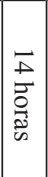 & ta & 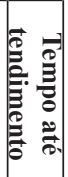 \\
\hline 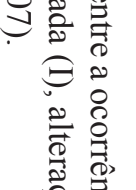 & 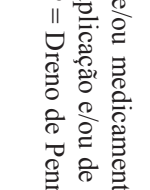 & 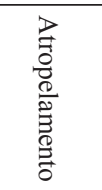 & 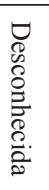 & 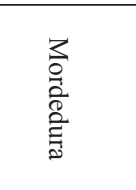 & 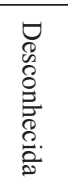 & 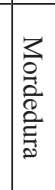 & 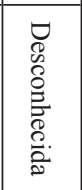 & 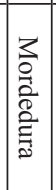 & 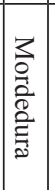 & 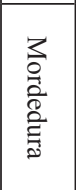 & 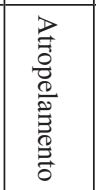 & 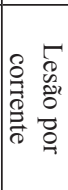 & 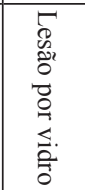 & 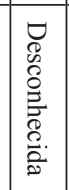 & \begin{tabular}{|l|}
3 \\
0 \\
0 \\
0 \\
0 \\
0 \\
$\vdots$ \\
0 \\
2
\end{tabular} & 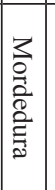 & 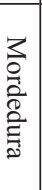 & & 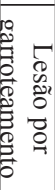 & 華 \\
\hline 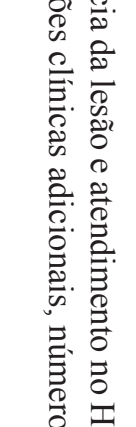 & 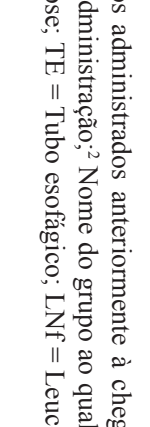 & $\begin{array}{l}\stackrel{\vec{e}}{E} \\
\stackrel{\vec{E}}{E}\end{array}$ & 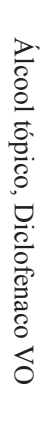 & $\begin{array}{l}\stackrel{\overrightarrow{0}}{\vec{E}} \\
\stackrel{\vec{E}}{E}\end{array}$ & 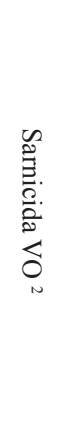 & 宫 & 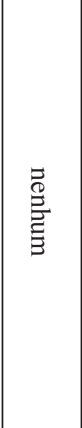 & 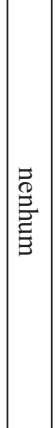 & 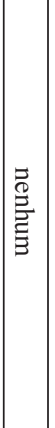 & 总 & 总 & 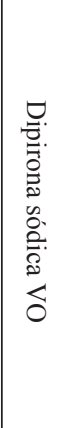 & 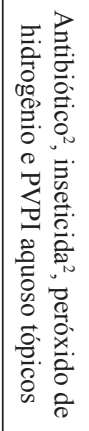 & 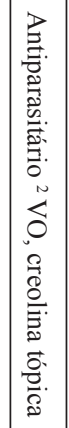 & 总 & 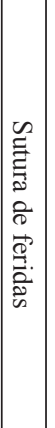 & 总 & 宫 & 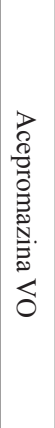 & 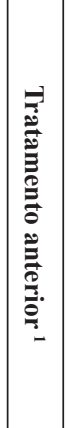 \\
\hline 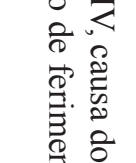 & 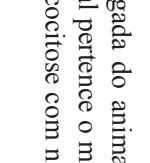 & 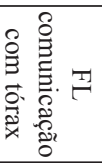 & T & 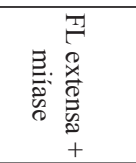 & $\begin{array}{l}\text { D } \\
0 \\
0 \\
0 \\
0 \\
0 \\
0\end{array}$ & T각 & 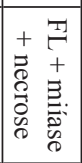 & 검 & T7 & Tr & 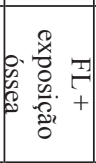 & 국 & T] & 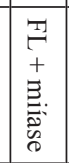 & 7 & 7 & 폭 & T3 & T] & 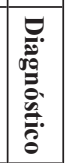 \\
\hline 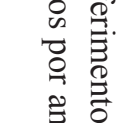 & 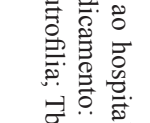 & $\Omega$ & - & - & - & $\Omega$ & - & 0 & $\Omega$ & $\Omega$ & - & - & - & - & $\Omega$ & -1 & $\Omega$ & - & - & $\begin{array}{l}\frac{2}{20} \\
\frac{0}{6}\end{array}$ \\
\hline 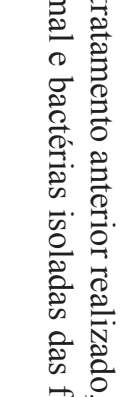 & 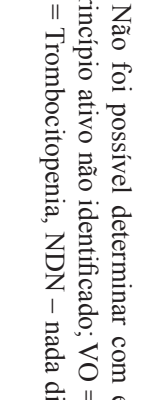 & 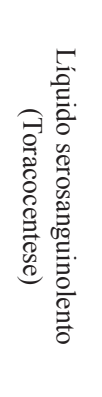 & $\underset{z}{z}$ & $\underset{z}{z}$ & 点 & $z$ & 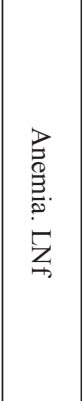 & 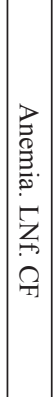 & $z$ & 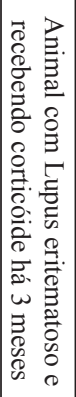 & $\underset{z}{z}$ & z & 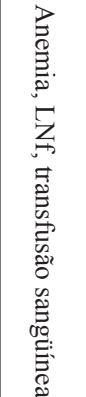 & 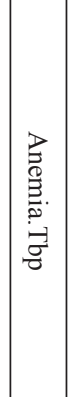 & $z$ & $z$ & $z$ & 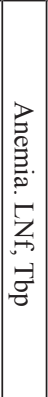 & $\underset{z}{z}$ & 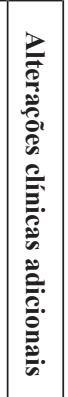 \\
\hline 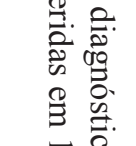 & 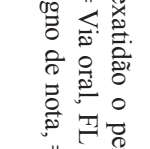 & - & - & - & $N$ & - & - & - & - & - & - & - & - & - & - & - & - & - & - & 范 \\
\hline 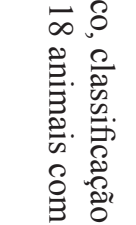 & 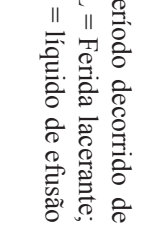 & $\begin{array}{l}\mathscr{W} \\
0 \\
\Xi \\
0 \\
0 \\
0 \\
0 \\
0 \\
0 \\
0 \\
0 \\
0\end{array}$ & 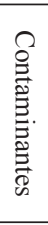 & 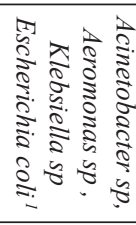 & 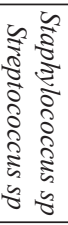 & $\mid \begin{array}{l}0 \\
0 \\
0 \\
\vdots \\
0 \\
0 \\
0 \\
0 \\
0 \\
0 \\
0\end{array}$ & $\begin{array}{l}0 \\
0 \\
\vdots \\
\vdots \\
\vdots \\
0 \\
0 \\
0 \\
0 \\
0\end{array}$ & \begin{tabular}{|c|}
0 \\
0 \\
0 \\
0 \\
0 \\
$\vdots$ \\
0 \\
0 \\
0 \\
$y$ \\
$y$
\end{tabular} & 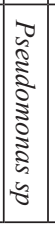 & $\begin{array}{l}0 \\
0 \\
0 \\
0 \\
\vdots \\
0 \\
0 \\
0 \\
0 \\
0\end{array}$ & 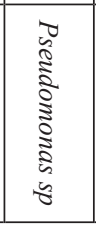 & $\begin{array}{l}7 \\
0 \\
0 \\
0 \\
0 \\
0 \\
0\end{array}$ & $\begin{array}{l}7 \\
0 \\
0 \\
\vdots \\
0 \\
0\end{array}$ & 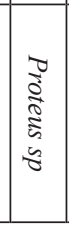 & 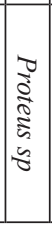 & 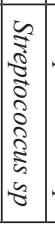 & 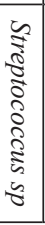 & 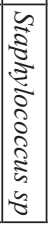 & 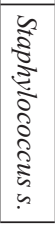 & 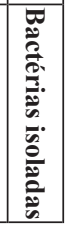 \\
\hline
\end{tabular}




\section{Resultados das culturas}

Em 14 animais houve crescimento de um só gênero de bactéria por cultura realizada e em um animal com dois ferimentos houve crescimento de gêneros distintos de bactérias (um gênero por ferimento). Em outro animal houve crescimento concomitante de bactérias de gêneros diferentes, sendo encontrado Acinetobacter sp, Aeromonas sp e Klebsiella sp na primeira cultura e Escherichia coli na segunda cultura realizada 20 dias após a primeira. Em uma cultura houve crescimento de contaminantes não sendo possível a identificação das bactérias e uma cultura foi negativa (Quadro 1).

De um total de 20 isolados bacterianos com o gênerobacteriano identificado, ogrupo predominante foi de bacilos Gram negativos (70,0\%). Dentre os gêneros, Pseudomonas foi o mais freqüente (30,0\%), seguido por Proteus (20,0\%), Staphylococcus e Streptococcus $(15,0 \%)$. Das feridas classificadas clinicamente como infectadas foram obtidos $70 \%$ dos isolados bacterianos. Os resultados de cada grupo e gênero estão na Tabela 1.

Tabela 1. Gêneros bacterianos isolados de feridas traumáticas de 18 animais internados no Centro Cirúrgico do Hospital Veterinário da Universidade Estadual de Londrina, separadas de acordo com a classificação das feridas em contaminadas ou infectadas (Londrina, 2006-2007)

\begin{tabular}{|c|c|c|c|}
\hline & $\begin{array}{l}\text { Isolados de feridas } \\
\text { contaminadas }(\mathrm{N})\end{array}$ & $\begin{array}{c}\text { Isolados de feridas } \\
\text { infectadas }(\mathbf{N})\end{array}$ & Total isolados $(\%)$ \\
\hline \multicolumn{4}{|l|}{ Gram positivos } \\
\hline Staphylococcus sp. & 0 & 3 & $3(15 \%)$ \\
\hline Streptococcus sp & 1 & 2 & $3(15 \%)$ \\
\hline \multicolumn{4}{|l|}{ Gram negativos } \\
\hline Proteus sp & 1 & 3 & $4(20 \%)$ \\
\hline Pseudomonas sp & 4 & 2 & $6(30 \%)$ \\
\hline Acinetobacter sp. & 0 & 1 & $1(5 \% 0$ \\
\hline Aeromonas sp. & 0 & 1 & $1(5 \%)$ \\
\hline Klebsiella sp & 0 & 1 & $1(5 \%)$ \\
\hline Escherichia coli & 0 & 1 & $1(5 \%)$ \\
\hline Total & $6(30 \%)$ & $14(70 \%)$ & $20(100 \%)$ \\
\hline
\end{tabular}

$\mathrm{N}=$ número; $\%$ = porcentagem

\section{Sensibilidade antimicrobiana}

$\mathrm{Na}$ tabela 2 encontram-se os resultados da sensibilidade antimicrobiana referentes às bactérias Gram negativas e na tabela 3 os resultados referentes às bactérias Gram positivas.

Todos os 14 isolados Gram negativos obtidos apresentaram índice MAR maior que 0,2 , sendo que os gêneros Acinetobacter, isolado do paciente 14, Proteus sp, isolado do paciente 6 e Pseudomonas $s p$, isolado do paciente 12 , foram resistentes a 14 antibióticos testados. Nenhum antibiótico testado nas bactérias Gram negativas apresentou eficácia maior do que 50\%. Nos antibióticos que foram testados em mais de quatro isolados bacterianos, houve $100 \%$ de resistência à amoxicilina + ácido clavulânico, cefalexina e cefalotina. Observouse $35,7 \%$ de sensibilidade à enrofoloxacina, $40 \%$ à gentamicina, $41,6 \%$ à ciprofloxacina e $50 \%$ à amicacina (Tabela 2).

Dos seis isolados Gram positivos isolados, cinco apresentaram índice MAR maior que 0,2. Considerando-se os antibióticos testados em quatro ou mais isolados Gram positivos, a amoxicilina + clavulanato apresentou eficácia de $75 \%$, seguido pela cefalexina, que apresentou eficácia de $66,7 \%$ (tabela 3). 


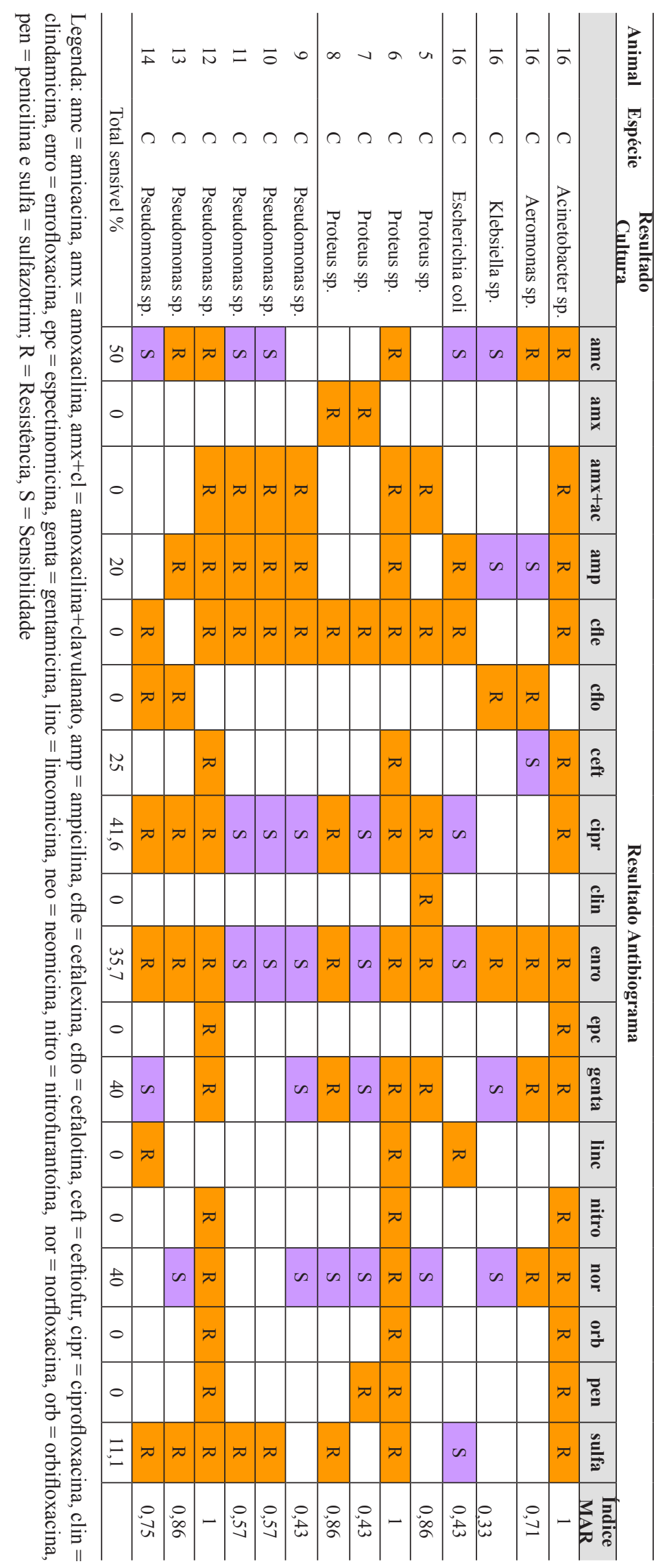

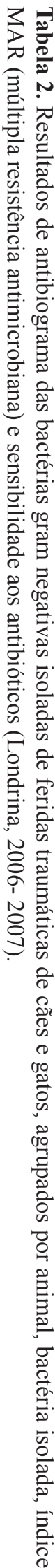




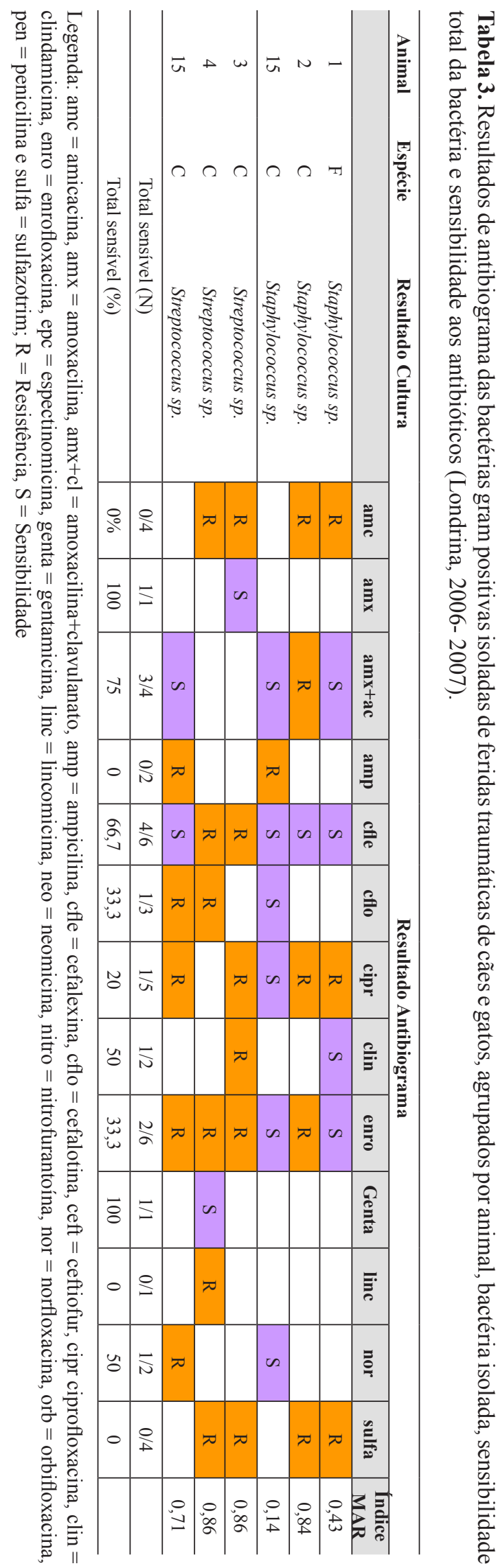


Na figura 1 está a porcentagem de sensibilidade antimicrobiana dos isolados Gram positivos, Gram negativos e da soma destes, a 11 antibióticos. Ao avaliar-se a sensibilidade das bactéris conjuntamente, o melhor índice foi obtido com o uso de norfloxacina $(58,33 \%)$, enquanto que medicamentos como amoxicilina + clavulanato, cefalosporina e sulfazotrim apresentaram no máximo $25 \%$ de eficácia.

Na figura 3 está a porcentagem de resistência e sensibilidade dos isolados separados por gênero. Com exceção da Klebsiella sp, todos os isolados apresentaram mais de $50 \%$ de resistência aos antibióticos testados (figura 2).

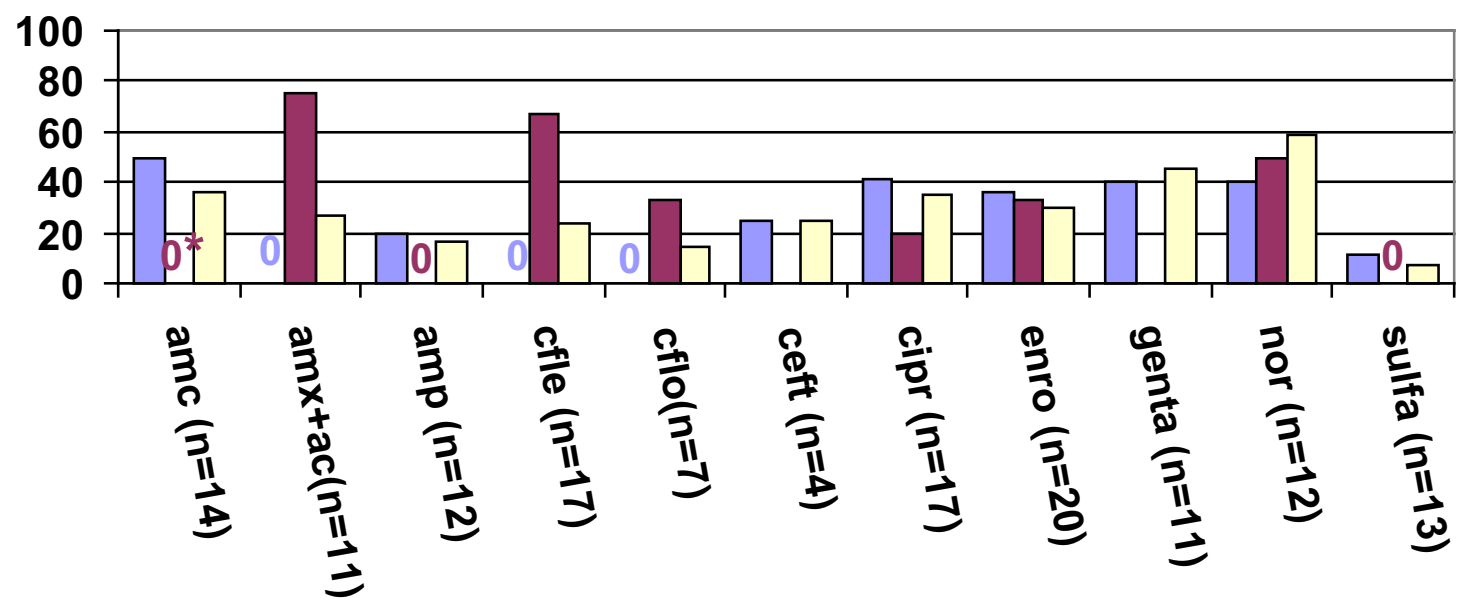

\section{Gram negativas $\square$ Gram positivas $\square$ Total}

* Zero (0) significa $0 \%$ de sensibilidade ao antibiótico ou $100 \%$ de resistência.

Figura 1. Porcentagem de sensibilidade antimicrobiana de bactérias Gram positivas, Gram negativas e das bactérias em sua totalidade a 11 antibióticos. (Londrina, 2006-2007).

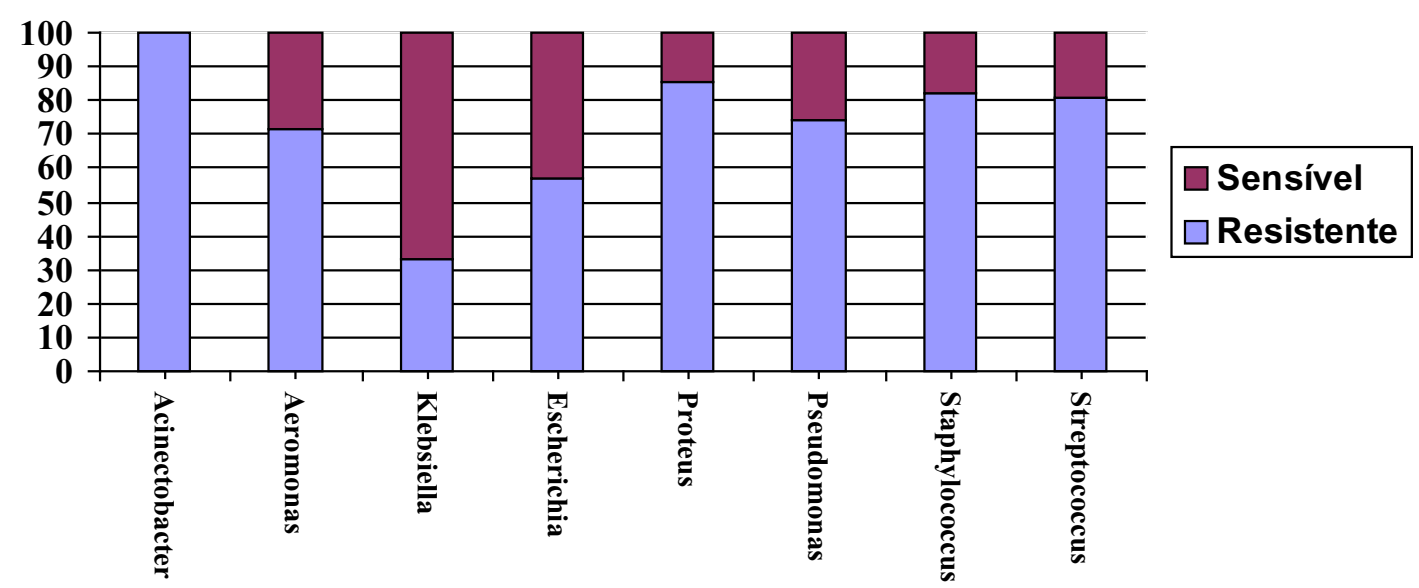

Figura 2. Porcentagem de resistência e sensibilidade antimicrobiana de isolados bacterianos de feridas contaminadas e infectadas em 16 animais (Londrina, 2006-2007). 


\section{Evolução dos casos}

Os antibóticos sistêmicos utilizados empiricamente desde o atendimento inicial, selecionados de acordo com o tipo, causa da ferida e estado clínico do paciente e os antibióticos sistêmicos selecionados após a realização de cultura e antibiograma encontram-se na Tabela 4. Em 13 de 16 casos houve a necessidade de realizar a troca do antibiótico empregado previamente. Em oito desses casos constatou-se que as feridas eram decorrentes de mordidas de outros cães.

Tabela 4. Antibióticos utilizados a partir do início do atendimento, resultado da cultura, antibiótico utilizado após o resultado da cultura e evolução do quadro nos 16 animais com feridas traumáticas contaminadas ou infectadas e cultura positiva (Londrina, 2006-2007).

\begin{tabular}{|c|c|c|c|c|}
\hline Animal & $\begin{array}{c}\text { Antibiótico utilizado a } \\
\text { partir do atendimento } \\
\text { inicial }\end{array}$ & Resultado da Cultura & $\begin{array}{c}\text { Antibiótico utilizado } \\
\text { após cultura e } \\
\text { antibiograma } \\
\end{array}$ & Evolução da ferida \\
\hline 1 & enrofloxacina SC-BID & Staphylococcus sp. & enrofloxacina VO-BID & Cicatrização \\
\hline 2 & $\begin{array}{l}\text { enrofloxacina SC-SID, } \\
\text { metronidazol VO-SID }\end{array}$ & Staphylococcus sp. & cefalexina SC-TID & Cicatrização \\
\hline 3 & Cefalotina SC-TID & Streptococcus sp. & amoxacilina VO-BID & Cicatrização \\
\hline 4 & $\begin{array}{l}\text { cefalexina IV-TID, } \\
\text { metronidazol IV-SID }\end{array}$ & Streptococcus sp. & $\begin{array}{l}\text { amoxacilina }+ \\
\text { clavulanato VO-BID }\end{array}$ & Cicatrização \\
\hline 5 & $\begin{array}{l}\text { cefalexina IV-TID, } \\
\text { metronidazol IV-SID }\end{array}$ & Proteus sp. & norfloxacina VO-BID & Cicatrização \\
\hline 6 & enrofloxacina VO-BID & Proteus sp. & $\begin{array}{l}\text { enrofloxacina VO-BID, } \\
\text { metronidazol PO-SID }\end{array}$ & Cicatrização \\
\hline 7 & $\begin{array}{l}\text { cefalexina IV-TID, } \\
\text { metronidazol IV-SID }\end{array}$ & Proteus sp. & enrofloxacina SC-BID & Cicatrização \\
\hline 8 & $\begin{array}{l}\text { cefalexina SC -TID, } \\
\text { metronidazol VO-SID }\end{array}$ & Proteus sp. & norfloxacina VO-BID & Cicatrização \\
\hline 9 & cefalexina IV-TID & Pseudomonas sp. & enrofloxacina SC-BID & Cicatrização \\
\hline 10 & cefalexina IV-TID & Pseudomonas sp. & enrofloxacina SC-BID & Cicatrização \\
\hline 11 & $\begin{array}{l}\text { cefalotina IV-TID, } \\
\text { metronidazol IV-SID }\end{array}$ & Pseudomonas sp. & enrofloxacina PO-BID & Cicatrização \\
\hline 12 & $\begin{array}{l}\text { cefalexina IV-TID, } \\
\text { metronidazol IV-SID }\end{array}$ & Pseudomonas sp. & cefalexina IV-TID & Desconhecida $^{1}$ \\
\hline 13 & cefalotina IV-TID & Pseudomonas sp. & norfloxacina VO-BID & Desconhecida $^{1}$ \\
\hline 14 & cefalotina SC-TID & Pseudomonas sp. & gentamicina IV-SID & Cicatrização \\
\hline 15 & $\begin{array}{l}\text { cefalexina IV-TID, } \\
\text { metronidazol IV-SID }\end{array}$ & $\begin{array}{l}\text { Staphylococcus sp., } \\
\text { Streptococcus sp. }\end{array}$ & $\begin{array}{l}\text { cefalexina IV-TID, } \\
\text { metronidazol IV-SID }\end{array}$ & Óbito \\
\hline 16 & cefalotina IV-TID & $\begin{array}{c}\text { Acinetobacter sp., Aeromonas } \\
\text { sp.+ Klebsiella sp., Escherichia } \\
\text { coli }\end{array}$ & $\begin{array}{l}\text { ampicilina SC-TID / } \\
\text { sulfazotrim SC-BID }\end{array}$ & Cicatrização \\
\hline
\end{tabular}

${ }^{1}$ Proprietário levou o animal antes do término do tratamento 
O manejo dos pacientes, o tratamento tópico instituído e a troca do antibiótico após cultura e antibiograma permitiram a boa evolução e cicatrização das feridas em 13/16 casos (81,3\%). Em dois casos não foi possível acompanhar a evolução clínica (Tabela 4).

No animal 12, isolou-se Pseudomonas $s p$ resistente à cefalexina utilizada durante o tratamento e a todos os outros 13 antibióticos testados. Entretanto, o tratamento tópico foi intensificado e o sistêmico foi mantido e um novo antibiograma não foi realizado devido a limitação financeira do proprietário. $\mathrm{O}$ animal 15 veio a óbito com sinais de sepse dois dias após ser internado, apesar do tratamento intensivo realizado. A cultura da secreção foi realizada logo que o animal foi internado. No resultado da cultura e antibiograma, disponibilizado após o óbito do animal, verificou-se que as bactérias Streptococus sp e Staphylococus sp isoladas eram sensíveis ao antibiótico utilizado.

Na cultura do material do animal 16, além do isolamento de Acinetobacter sp resistente a 14 antibióticos testados, após quatro dias isolou-se concomitantemente Aeromonas sp e Klebsiella sp, ambas sensíveis à ampicilina, instituída como novo tratamento. Porém, não houve evolução favorável da ferida, realizando-se nova cultura após 20 dias, com isolamento de Escherichia coli tratada com sulfazotrim, ocorrendo a cicatrização. No animal 4 isolou-se Streptococcus sp sensível somente à gentamicina, dentre os antibióticos testados, porém por se tratar de um paciente com 50 dias de idade, este antibiótico aminoglicosídeo não foi utilizado pelo seu potencial nefrotóxico, optando-se pelo uso empírico de amoxacilina + clavulanato, não testado no antibiograma, mas que tem potencial para atuar contra bactérias gram-positivas, havendo resolução do quadro.

\section{Discussão}

\section{Dados clínicos-terapêuticos iniciais}

Metade das feridas foi decorrente de mordidas e 11 já estavam infectadas no momento do primeiro atendimento. Em seres humanos quatro a $20 \%$ das mordidas de cães tornam-se infectadas, e esta infecção se desenvolve 8 a 24 horas após a lesão (GREENE; GOLDSTEIN, 2006). Segundo Pavletic e Trout (2006), todas as feridas causadas por mordidas, mesmoasrecentes, devemserconsideradas contaminadas, pois contém flora polimicrobiana aeróbica e anaeróbica proveniente da cavidade oral do agressor, associadas às bactérias da pele da vítima e do meio ambiente. Para Krawhwinkel e Boothe (2006), todos os tipos de feridas possuem algum risco de se tornarem infectadas e colonizadas por uma ampla variedade de microorganismos, como constatado no presente trabalho. Segundo Greene e Dearmin (2006), a imunossupressão do paciente devido à doença sistêmica ou administração de fármacos imunossupressores, como observado no animal 10, pode aumentar o risco para ocorrência de infecção.

\section{Resultado das Culturas}

Foi possível isolar e identificar amostras bacterianas do material proveniente de 16 dos 18 pacientes testados. Vários agentes podem ser encontrados em ferimentos contaminados e infectados de cães e gatos, conforme a causa do ferimento (GREENE; DEARMIN, 2006). Segundo Amalsadvala e Swaim (2006) podem existir vários tipos de microorganismos em um mesmo ferimento, principalmente Pseudomonas sp, Streptococcus spe Staphylococcus sp, como observado neste trabalho, sendo importante diferenciar microorganismos encontrados na superfície daqueles realmente responsáveis pelas complicações. 
No presente trabalho as bactérias Gram negativas foram mais freqüentes. É importante lembrar que não foi realizada cultura anaeróbica e agentes importantes podem não ter sido identificados, já que a flora oral canina é rica em organismos anaeróbicos (DAVIDSON, 1998a). Em um paciente do qual foi coletado efusão proveniente do tórax, o resultado foi negativo provavelmente pela falta deste exame, já que é mais comum ocorrer contaminação do tórax por bactérias gram-negativas e/ou anaeróbicas (GREENE; DEARMIN, 2006). O animal recuperouse provavelmente pelo uso empírico de antibióticos de amplo espectro com ação em anaeróbios, associado ao uso de dreno torácico e lavagem pleural.

Dentre os Gram negativos isolados, Pseudomonas e Proteus foram os gêneros mais encontrados. Segundo Kruth (2006) estas bactérias são agentes oportunistas, que podem ser transmitidos para outros animais e o homem. Dos seis pacientes que apresentaram Pseudomonas, quatro foram mordidos por outros animais, um foi atropelado e um apresentou ferimento de causa desconhecida. Como este microorganismo também é um importante agente nosocomial, que sobrevive bem em meio hospitalar, deve-se realizar medidas de prevenção para evitar sua disseminação a pacientes internados com outras afecções. Já para Davidson (1998a), a Pasteurella multocida seria o agente mais freqüentemente encontrado em feridas decorrentes de mordidas, o que não foi constatado neste trabalho. Para Meyers et al. (2008), Pasteurella canis e streptococcus piogênicos foram mais comuns em feridas infectadas.

\section{Sensibilidade antimicrobiana}

O índice de multiresistência observado em todos os isolados Gram negativos e em cinco de seis isolados Gram positivos confirma as observações de Mateu e Martin (2001), que constataram um aumento progressivo e gradativo de resistência aos antibióticos nos últimos 15 anos na Medicina Veterinária, dificultando o controle de várias afecções.
Pseudomonas foi o gênero predominante dentre os bacilos Gram negativos responsáveis pela maioria das feridas que evoluíram desfavoravelmente. Segundo Kruth (2006) a gentamicina, amicacina e a ciprofloxacina poderiam ser eficientes contra este agente, sendo a enrofloxacina ineficaz em muitos casos, porém neste estudo constatou-se que a enrofloxacina foi eficiente em três de seis casos. Conforme citado ainda por Kruth (2006), a terapia contra esta bactéria é extremamente difícil devido à ocorrência de resistência natural e adquirida. Assim, para este autor é essencial a realização de cultura e antibiograma em todos os casos suspeitos de infecção por Pseudomonas sp.

Nos outros gêneros a susceptibilidade antimicrobiana também foi extremamente baixa e variável, não havendo um antibiótico empírico que possa ser escolhido com mais segurança no início do tratamento, reforçando a necessidade da realização de cultura e antibiograma para nortear o tratamento (DAVIDSON, 1998b; DERNELL, 2006).

Em casos de mordidas, Greene e Golsdstein (2006) sugerem a seleção de antibióticos de amplo espectro que sejam eficazes contra a maioria dos microorganismos da microflora oral. A cefalexina e a cefalotina, usadas a partir do atendimento inicial em mais da metade dos casos, são cefalosporinas de primeira geração, consideradas ativas contra bactérias gram positivas e algumas gram negativas aeróbias (GREENE; WATSON, 2006). No presente estudo não se mostraram eficazes em evitar a infecção "in vivo", ocorrendo ainda grande resistência bacteriana em todos os isolados Gram negativos e em quase metade dos Gram positivos, não senso assim fármacos de eleição no tratamento de feridas contaminadas e infectadas, principalmente nas decorrentes de mordidas.

Segundo Pavletic e Trout (2006), os antibióticos mais indicados para tratamento das feridas traumáticas são os bactericidas de amplo espectro como cefalosporinas, amoxicilina + clavulanato e fluorquinolonas, porém neste trabalho mesmo as 
fluorquinolonas não apresentaram "in vitro" eficácia maior do que 58\%. Diferentemente de Meyers et al. (2008), que constataram em bactérias isoladas de feridas contaminadas e infectadas susceptibilidade "in vitro" à antibióticos como amoxicilina + clavulanato, cefalosporinas de primeira geração e sulfa potencializada em porcentagens acima de $80 \%$, no presente trabalho a susceptibilidade a estes três fármacos não alcançou $25 \%$.

Para Pavletic e Trout (2006) o uso de antibióticos no manejo de feridas causadas por mordidas permanece controverso. A administração imediata de antibióticos intravenosos seria indicada para prevenir a infecção em pacientes com lesões graves, enquanto que em humanos a administração destes fármacos é considerada terapêutica e não profilática. Segundo Krawhwinkel e Boothe (2006), a administração de antibióticos deve ser considerada quando a fáscia muscular foi comprometida, ou permanece tecido de viabilidade questionável após o debridamento, ou o animal está severamente imunocomprometido, ou sinais de infecção sistêmica estão presentes.

Alguns autores preconizam a realização de exame bacterioscópico com coloração de Gram no início do atendimento de animais com feridas traumáticas, para orientar na escolha do antibiótico (DAVIDSON, 1998b; KRAWHWINKEL; BOOTHE, 2006; DERNELL, 2006 ). Para outros autores a realização de cultura em feridas recentes e ainda não infectadas poderia ser útil na determinação prévia dos organismos potencialmente infecciosos (ARIAS; PEREIRA, 2002; PAVLETIC; TROUT, 2006). Esta coleta deve ser obtida da profundidade da ferida para evitar o crescimento de contaminantes (PAVLETIC; TROUT, 2006). Em ambos os casos o clínico deve estar preparado para alterar a medicação com base nos resultados da cultura, na falta de cicatrização adequada após dois a três dias ou piora da condição do paciente, lembrando que a antibioticoterapia sistêmica não substitui o tratamento tópico das feridas e não evita a ocorrência de infecção (GREENE; GOLDSTEIN, 2006, PAVLETIC; TROUT, 2006), como constatado no presente trabalho, pois houve necessidade de realizar a troca do antibiótico em 13 de 16 casos.

No animal 12 detectou-se Pseudomonas $s p$ resistente à cefalexina que estava sendo utilizada e à outros 13 antibióticos testados. Conforme Kruth (2006), embora esta bactéria possa ser isolada de trato respiratório, genital, gastrintestinal e pele, o número de microrganismos geralmente é controlado por competição com a flora bacteriana normal e a inflamação ou lesão das mucosas e uso crônico de antibióticos pode levar à sua proliferação. Pode ocorrer também que feridas abertas e incisões cirúrgicas tornem-se contaminadas e subseqüentemente infectadas com cepas multiresistentes do meio hospitalar (KRUTH, 2006), assim, a permanência de animais internados para tratamento de feridas e que sejam portadores destas bactérias multiresistentes, poderia colocar em risco animais internados no mesmo local por outros motivos, principalmente no caso de patógenos oportunistas como o Acinetobacter sp., responsável por muitas infecções nosocomiais (FRANCEY et al., 2000).

\section{Evolução dos Casos}

O manejo das feridas na forma aberta conforme preconizado por Greene e Golsdstein (2006), através da lavagem e aplicação de bandagens, associado à antibioticoterapia com base no resultado da cultura e antibiograma, favoreceu a boa evolução de $81,3 \%$ dos casos. Em um caso, mesmo não sendo feita a troca do antibiótico, houve melhora do quadro após a intensificação do tratamento tópico, o que está de acordo com Heldlund (2002) e Greene e Dearmin (2006), que afirmam que a cicatrização de feridas é um processo influenciado por vários fatores, principalmente o estado clínico do paciente, características da ferida e tipo de agente infeccioso presente. Em pacientes idosos, imunossuprimidos ou com doenças sistêmicas (HELDLUND, 2002), algumas bactérias encontradas emferidas traumáticas podem se difundir levando a sepse e óbito, mesmo 
com o tratamento adequado (GREENE; DEARMIN, 2006), conforme observado em um caso.

\section{Conclusão}

A maioria dos isolados bacterianos obtidos das feridas traumáticas contaminadas e infectadas foram microorganismos Gram negativos, que apresentaram multiresistência "in vitro" aos antibióticos testados. Após a determinação da sensibilidade antimicrobiana e uso do antibiótico correto, associado ao manejo da ferida na forma aberta, houve boa evolução da cicatrização. Os antibióticos utilizados no início do tratamento foram inadequados em grande parte dos casos, principalmente quando se utilizou cefalosporina de primeira geração.

As bactérias isoladas neste estudo e principalmente sua sensibilidade antimicrobiana, foram diferentes da bibliografia compilada, sendo imperativo a realização de mais estudos nesta área no Brasil. Nenhum antibiótico apresentou eficácia "in vitro" maior do que $60 \%$, dificultando a indicação de um antibiótico para uso empírico em casos semelhantes, enfatizando a necessidade de avaliação cuidadosa dos casos de ferimentos traumáticos, contaminados e infectados. Sugerese a realização de testes de identificação das bactérias e sua sensibilidade antimicrobiana para evitar o uso inadequado de antibióticos com conseqüente surgimento de resistência precoce de microorganismos potencialmente patogênicos em casos semelhantes.

\section{Agradecimentos}

À Universidade Estadual de Londrina e ao CNPq, pela concessão de duas bolsas de iniciação científica, sendo uma PIBIC/UEL e outra CNPq.

\section{Referências}

AMALSADVALA, T.; SWAIM, S. Management of hard to heal wound. The Veterinary Clinics of North America: Small Animal Practice, Philadelphia, v. 36, n. 4, p. 693711, 2006.

ARIAS, M. V. B.; PEREIRA, A. M. Manejo de feridas em cães e gatos - revisão. Revista Clínica Veterinária, São Paulo, v. 7, n. 38, p. 33-42, 2002.

BAUER, A. W.; KIRBY, W. M. M.; SHERRIS, J. G. Antibiotic susceptibility testing by standardized single disc method. American Journal of Clinical Pathology, Philadelphia, v. 45, n. 4, p. 493-496, 1966.

CARTER, G. R. Fundamentos de bacteriologia e micologia veterinária. São Paulo: Roca, 1988.

DAVIDSON, E. B. Managing bite wounds in dogs and cats: part I. The Compendium on Continuing Education for the Practicing Veterinarian, Princeton, v. 20, n. 7, p. 811-20, 1998a.

. Managing bite wounds in dogs and cats: part II. Compendium on Continuing Education for the Practicing Veterinarian, Princeton, v. 20, n. 9, p. 974-91, 1998b.

DERNELL, W. S. Initial wound management. The Veterinary Clinics of North America: Small Animal Practice, Philadelphia, v. 36, n. 4, p. 713-38, 2006.

FRANCEY, T. F.; GASCHEN, F.; NICOLET, J.; BURNENS, A. P. The role of Acinetobacter baumannii as a nosocomial pathogen for dogs and cats in an intensive care unit. Journal of Veterinary Internal Medicine, Lawrence, v. 14, n. 2., p. 177-183, 2000.

GREENE, C.E.; DEARMIN, M. G. Surgical and traumatic wound infections. In: GREENE, C. E. Infectious diseases of the dog and cat. 3.ed. Saint Louis: Saunders/Elsevier, 2006. p. 524-531.

GREENE, C. E.; GOLDSTEIN, J. C. Bite wound infections. In: GREENE, C. E. Infectious diseases of the dog and cat. 3.ed. Saint Louis: Saunders/Elsevier, 2006. p. 495-510.

GREENE, C. E.; WATSON, D. J. Antibacterial chemotherapy. In: GREENE, C. E. Infectious diseases of the dog and cat. 3.ed. Saint Louis: Saunders/Elsevier, 2006. p. 274-301.

HEDLUND, C. H. Surgery of the integumentary system. In: FOSSUM, T. W. Small animal surgery. 2.ed. Missouri: Mosby, 2002. p. 60-68. 
KRAHWINKEL, D. J.; BOOTHE, H. W. Topical and systemic medications for wounds. The Veterinary Clinics of North America: Small Animal Practice, Philadelphia, v. 36, n. 4, p. 739-57, 2006.

KRUMPERMAN, P. H. Multiple antibiotic resistance indexing of Escherichia coli to identify high-risk source of fecal contamination of foods. Applied Environmental Microbiology, Oxford, v. 46, n. 1, p. 165-170, 1983.

KRUTH, S. A. Gram-negative bacterial infections. In: GREENE, C. E. Infectious diseases of the dog and cat. 3.ed. Saint Louis: Saunders/Elsevier, 2006. p. 320-330.
MATEU, E.; MARTIN, M. Why is anti-microbial resistance a veterinary problem as well? Journal of Veterinary Medicine: Series B, Berlin, v. 48, n. 8, p. 569581, 2001.

MEYERS, B.; SCHOEMAN, J. P.; GODDARD, A.; PICARD, J. The bacteriology and antimicrobial susceptibility of infected and non-infected dog bite wounds: Fifty cases. Veterinary Microbiology, Amsterdam, v. 127, n. 3-4, p. 360-368, 2008.

PAVLETIC, M. M.; TROUT, N. J. Bullet, bite, and burn wounds in dogs and cats. The Veterinary Clinics of North America: Small Animal Practice, Philadelphia, v. 36, n. 4, p. 873-93, 2006. 